\title{
LA CLASE MEDIA BRASILEÑA Y EL ARQUETIPO DE PREJUICIO DE CLASSE
}

\section{ARTÍCULO ORIGINAL}

GIESBRECHT, Daniel Florence ${ }^{1}$

GIESBRECHT, Daniel Florence. La clase media brasileña y el arquetipo de prejuicio de clase. Revista Científica Multidisciplinar Núcleo do Conhecimento. Año 05, Ed. 02, Vol. 04, págs. 104-124. Febrero de 2020. ISSN: 2448-0959, Enlace de acceso: https://www.nucleodoconhecimento.com.br/historia-es/arquetipo-de-prejuicio

\section{RESUMEN}

Este artículo tiene como objetivo elaborar una reconstitución histórica, a partir del serial a largo plazo, la formación de la clase media brasileña y también su arquetipo de prejuicio de clase. Utilizamos como punto de partida para nuestra reflexión el hecho de que Brasil vivió más de trescientos años de esclavitud, lo que legó la profusión de un imaginario racista, dando lugar a prácticas prejuiciosas y naturalizada a poblaciones afrodescendientes, además de haber extendido al pobre ciudadano, en general. Tratamos de relacionar de manera historicista los objetos estudiados con los conceptos sociológicos de la socialización, además de caracterizar las ideas burguesas de la clase media y las élites brasileñas de la historia de las mentalidades. Pretendemos contribuir a una mejor comprensión de los obstáculos creados por la falta de prácticas de oversionalidad en las relaciones sociales diarias.

Palabras clave: Clase social, prejuicio, esclavitud, exclusión social, oposición.

1 Estudiante de doctorado en Historia Contemporánea; Máster en Educación; Licenciado en Ciencias Sociales, Grado en Pedagogía, Grado en Historia. 


\section{INTRODUCCIÓN}

Cuando investigamos indicadores económicos sobre el potencial brasileño, notamos un número consistente y alto, muy competitivo en comparación con otros países, tanto que Brasil, desde la década de 1960 hasta la actualidad, siempre está entre los quince países con el producto interno bruto más alto del mundo.

Las cifras no se repiten si buscamos datos de referencia sobre las tasas de pobreza y desigualdad. Las alarmantes realidades de distribución de ingresos, altas tasas de violencia, mortalidad infantil, entre otros, se perciben fácilmente a los ojos de quienes viajan por el vasto territorio brasileño, dando la impresión de estar paseando por dos mundos completamente diferentes: el de la opulencia y el de la miseria, una ilusión de óptica de una economía insertada con éxito en el escenario mundial, pero que enmascara una compleja realidad social , que presenta, en su estructura, marcas de profunda desigualdad.

Usaremos la palabra "pobreza" para referirse a la situación de millones de personas que viven en Brasil. Pero el concepto de pobreza, dependiendo del contexto utilizado y de su factoring semántico, se vuelve complejo y polisémico. Es a partir de esta complejidad semántica que proponemos inferir nuestra reflexión a través de este artículo, relacionando la pobreza con el arquetipo de la formación de la clase media brasileña y sus interrelaciones de clase.

En el imaginario intrínseco de la clase media brasileña en sus círculos de socialización, la imaginería de la pobreza se transfigura en una percepción tan simplificada de la realidad que los rodea, hasta el punto de que el individuo de la clase subalterna, a menudo en un estado de inseguridad, adquiere inconscientemente el discurso de la clase a la que no pertenece y por la que es explotada. En esta situación, no es difícil encontrarse con frases cotidianas del sentido común más puro que buscan, en todo momento, una explicación de los males de las desigualdades del país: "Es pobre porque es un vagabundo", "Pobre no le gusta trabajar" o, aún, "Pobre no saben hacer nada y no pueden aprender nada". 
Frases como estas terminan produciendo una naturalización de lo social, es decir, se aferra al carácter histórico y social de un hecho reduciéndolo a un evento natural. Así, algo así como la falta deja de ser visto como resultado de una estructura reunida a priori, que termina legitimando las desigualdades en su praxis, para ser considerado un atributo personal de un individuo.

Tomando como referencia la idea de la naturalización de las desigualdades y la individualización de las expectativas y fracasos ad hoc, es necesario un reflejo preciso de los factores de clase que contribuyen a la naturalización del arquetipo de inferiorización de los grupos sociales en desventaja y que rompe los modelos preconcebidos desde la llegada del positivismo histórico del siglo XIX que, transformando las ciencias sociales en naturaleza gobernada por leyes inmutables que escapan al control humano, inducir el conformismo, la aceptación pasiva y resignada de lo que se produce histórica y socialmente (Sucupira, 1984). El arquetipo de los pobres que fracasan a diario, tan arraigado en el imaginario colectivo brasileño desde la colonia hasta la contemporaneidad, es en este sentido una operación ideológica, que sirve para mantener un cierto orden social, es decir, una configuración de vida económica que beneficia a las clases sociales que producen esta ideología.

Primero utilizaremos el marco teórico de Souza (2019), que parecía más pertinente a la crítica de los paradigmas que guían el pensamiento social brasileño, especialmente el del "culturalismo", en sus intentos de explicar los orígenes de las desigualdades en el país. También es nuestra intención presentar al lector las ideas que defenderemos a posteriori, especialmente que la estructuración del arquetipo mental de la clase media brasileña es uno de los principales obstáculos para la construcción de un país que consolida los valores republicanos, y que crea condiciones para la expansión de los derechos de ciudadanía para millones de sus habitantes.

\section{POLISSEMIA DE POVERTY}

La pobreza es un fenómeno histórico y social. Esto significa que está estrechamente relacionado con la estructura de la sociedad y la forma en que cada clase social se 
apropia de los bienes producidos o de la riqueza generada. No es un concepto fácil, pero podemos utilizar diferentes criterios para tratar de definirlo.

El criterio de los ingresos personales o familiares ha sido el más utilizado en Brasil, pero creemos que es impreciso, debido a muchos factores que incluso han empeorado en los últimos años, como el crecimiento de las actividades informales, que impide un control efectivo de los ingreso[2]s.

Además de los ingresos, otro criterio utilizado para configurar la pobreza es verificar lo que se considera esencial para la reproducción de la vida. Por lo tanto, a nuestro juicio, este criterio también es reduccionista porque, debido a los convenios internacionales, sólo relaciona la pobreza con el consumo de alimentos.

Parece más pertinente ampliar el concepto a "necesidades básicas", que no se limitarían sólo a los alimentos, sino que incluirían otros aspectos considerados indispensables para la reproducción material de la existencia, ampliando la idea de pobreza para que la incapacidad de alguien o una familia tenga medios que permitan el acceso a un conjunto de elementos considerados esenciales para la supervivencia. Esto también se configuraría si la persona o familia es excluida del sistema educativo, ya que la escolarización hoy en día es esencial para entrar en el mercado laboral. Según estudios de Rocha (2006), sólo con la expansión de estos conceptos pudimos entender un país de dimensiones continentales como Brasil, inmerso en enormes disparidades regionales.

Nuestra idea argumentativa es superar exactamente la visión material de la constitución del concepto de pobreza para una valorización psicológica y estructural abstracta e inconsciente que, en la construcción histórica brasileña, legitima este concepto anclado en un marco metodológico apoyado por el arquetipo de prejuicio, que inferiora a los grupos sociales constituidos en un país que tuvo, durante más de trescientos años, las marcas diarias de una economía y sociedad orientadas a expensas del trabajo esclavo. 
Los prejuicios pueden servir a diferentes intereses materiales, que pueden ser: clase, género, político, racial o étnico y religioso. Pero para demostrar la constitución de prejuicios naturalizados por la clase media brasileña, sin duda necesitamos conocer las estructuras históricas que sintetizaron, a través del pasado precapitalista, las distancias entre los grupos sociales de una sociedad que, desde la bipolaridad entre usted y el esclavo, se movió hacia una organización más compleja con la llegada del capitalismo comercial e industrial, pero que siempre ha mantenido el arquetipo del pasado esclavo.

La discriminación y los prejuicios también pueden producir sentimientos de renuncia y conformidad en las víctimas, que aceptan ser oprimidas y explotadas, como Sartre (1905-1980) advirtió en una obra titulada The Respectful Prostitute[3] (1946). Nos parece el caso brasileño, con actitudes diarias de su clase media de inferiorización de los menos favorecidos, haciendo que introjan sus propios prejuicios y la idea del fracaso, creyendo que merecen tales discriminaciones.

\section{ORIGINAS HISTÓRICAS DE PREJUICIO DE LA CLASE MIDDLE BRASILIAN}

Entre los siglos XVI y XIX, el comercio de esclavos africanos con América vinculó los dos continentes a lo que se convertiría en el comercio más lucrativo de la historia brasileña. Los esclavos africanos estuvieron presentes en las más diversas actividades cotidianas. La naturalización de la esclavitud se ha convertido en algo tan arraigado en las estructuras de la sociedad que es muy improbable que se imagine sin las divisiones tradicionales de aquellos que mandaron y obedecieron. Este modelo autoritario de relaciones sociales permite comprender la permanencia simbólica practicada contra las poblaciones más pobres, incluso después de la abolición de la esclavitud a finales del siglo XIX.

Con el desarrollo del pensamiento social brasileño, especialmente desde principios del siglo XX, hemos tratado de explicar el panorama dicotómico que experimenta la sociedad nativa a lo largo de su historia. Creemos que, para esta tarea, la teoría más apropiada, promoviendo una mejor comprensión de la construcción de esta estructura 
social, es la de la historia serial, presente en las metodologías de fernand braude[4]l. Contemplar un análisis semiótico de la formación de las clases sociales brasileñas sólo es posible cuando percibimos el serial de la larga duración de la esclavitud, que validó en la mentalidad diaria del país el arquetipo de prejuicio, distanciamiento y segregación, de casa-grande a senzala, que, con la transición a la modernidad de la fase mercantil e industrial del capitalismo, corroboró una nueva forma de explotación , pero con la ropa estructural de los viejos, segregando a ricos y pobres dentro de las grandes ciudades, así como en los círculos sociales.

También vale la pena recordar que el desarrollo de clases en Brasil, según Fausto (1997), está relacionado con la consolidación de una clase propietaria, que posee la propiedad de la tierra y otros medios de producción. En un país que una vez fue fundamentalmente agrícola, esta clase se apropiaba fácilmente de la mayor parte de la riqueza producida, ya que explotaba la mano de obra esclavizada.

Bajo los auspicios de la sociedad colonial, se desarrolló de una manera muy particular en las regiones donde se consolidó el sistema de plantaciones, las relaciones sociales fuera de la esclavitud entre los hombres libres y los propietarios. Con la ausencia de un sistema colonial directo, además de una inmensidad territorial, que dificultó la implementación de formas optimizadas de control bajo la tutela de la corona portuguesa, y la creación del sistema de distribución de capitanías hereditarias -un intento de conciliación público-privada en el proceso de colonización-se desarrollaron formas ambiguas, contradictorias y desreguladas de relaciones entre individuos de diferentes clases. Es en este escenario que encontramos la figura del agregado.

Este estrato intermedio de personas formalmente libres, entre amos y esclavos, está formado por hombres y mujeres dependientes, tanto material como simbólicamente de terratenientes y personas. En el sentido más económico y material, la dependencia de este extracto social es inexorable. (...) Esto constituye entre nosotros, como forma económica, política y social, la figura del "agregado". Figura fundamental en la literatura brasileña y la sociología histórica, el agregado formará la 
primera clase intermedia entre propietarios y desposeídos. (Sousa, 2018: 65-66).

Aunque todavía distante del surgimiento de la clase media brasileña moderna, el grupo de hogares, incluso dependientes y a menudo engrosados las estadísticas de la población desposeída -la pérdida de la protección de su "padrino" era suficiente es de suma importancia entender la introjección mental de los prejuicios entre las futuras clases sociales del Brasil moderno, dado que éstas, dentro de un sistema de dominación autoritaria del poder privado sobre el público , fue precisamente la casta la que naturalizó los principios de control y violencia practicados de una manera, hasta cierto punto, sádica por las élites ruralistas que trabajan esclavos, quienes también delegaban en los agregados los derechos a oprimir a los vistos como "instrumentos que hablaban", bestializados y deshumanizados.

El hecho de que nos interese desde aquí es darse cuenta de que fue a través de esta relación de interdependencia entre señores y agregados, además del monopolio de la fuerza establecido por debajo del estado como organizador de la sociedad, que el sentimiento de desprecio por el otro era conducir a la constitución de comportamiento sádico con los esclavizados y los más humildes. El placer de la violencia se verifica comúnmente en la historia de estas clases intermedias en la sociedad brasileña, hasta el punto de ser más intensos - allí percibimos el sadismo [5]como una forma de reconocimiento grupal, o superioridad sobre el otro - como una práctica cotidiana de aquellos a quienes llamamos hombres libres. Escenas de humillación, chistes, sátiras y comportamiento obtuso serán parte del alcance del tratamiento perpetrado en los marginados, que llamaremos "escoria" social.

Desde el inicio de la actividad minera en el crepúsculo del siglo XVII y a lo largo del siglo XVIII, Brasil experimentó el fenómeno de la urbanización, concentrado principalmente en la capitanía de Minas Gerais. La sociedad estratificada del azúcar del noreste era la de un carácter más dinámico y multifacético en Vila Rica. La esclavitud y la libertad iban de la mano en una economía interdependiente, pero proporcionaba nuevas formas de ascensión social, incluidos los transatlánticos negro[6]s. La experiencia minera fue peculiar, en la que el mestizo, los negros y los 
indios tuvieron un momento único en el que pudieron poner en práctica por primera vez sus talentos, de ahí el gran número de artistas, artesanos, contadores y la aparición de varias otras profesiones en la región. Por primera vez en la historia de Brasil, un conocimiento técnico más expresivo parecía diferenciarse de una sociedad construida por el trabajo "crudo" y manual, allanando el camino para el surgimiento de la clase media moderna.

A principios del siglo XIX fue el presagio de nuevos aires que sacudirían el continente europeo, y su mayor tormenta fue Napoleón Bonaparte. Las guerras iniciadas por el emperador francés se asociaron, además de sus ambiciones megalómanas, con la nueva forma asumida por el sistema capitalista en su etapa industrial. Francia, el enemigo histórico de Gran Bretaña, estaba iniciando un conflicto de proporciones continentales para apoderarse de su parte justa, en un augurio de lo que sería el fenómeno imperialista aún por desencadenar a mediados del siglo. Este hecho tendría un impacto directo e indirecto en el futuro de Portugal y, en consecuencia, de Brasil, porque la estructura administrativa metropolitana cruzaría los mares para establecerse en la colonia.

Este proceso, que la familia real portuguesa llegó a consolidar, ya estaba previsto en el descubrimiento de minas, en presencia de algunas ciudades coloniales de expresión, en la necesidad de una mayor vigilancia sobre la riqueza recién descubierta y un mayor control, a partir de entonces, sobre el familismo y el mandonismo privado. Un ejemplo sintomático del paso del poder del campo a las ciudades es el caso de las deudas de los patriarcas rurales antes incobrables, desde entonces pagados bajo la fuerza policial. Tan importante como el cambio del centro económicamente dinámico del Noreste al Sureste fue la transformación social de grandes proporciones, lo que implica nuevos hábitos, nuevos roles sociales, nuevas profesiones y, al final del día, la construcción de una nueva jerarquía social. (Souza, 2019: 61).

La urbanización finalmente representó un cambio de tamaño de las estructuras de poder, haciendo que pasara del patriarcalismo individual a las manos del estado que 
se organizó. Desde una perspectiva weberiana, el monopolio legítimo de la violencia comenzó a centrarse en las manos de aparatos estatales, como la policía, por ejemplo, fusionándose con las prerrogativas de las antiguas formas de autoritarismo de clase, pero manteniendo la práctica del sadismo, anteriormente privadamente, ahora perpetrada por las fuerzas públicas.

Con la apertura de los puertos a las naciones amigas en 1808, decretada por el entonces príncipe regente $\mathrm{D}$. Joao $\mathrm{VI}$, y con la firma de los tratados de comercio y navegación de 1810, Brasil experimentaría transformaciones que afectarían inmediatamente su estructura colonial. El entorno de las ciudades portuarias, principalmente Río de Janeiro, Salvador y Recife se convirtieron, durante la noche, en centros comerciales ocupados, con la entrada de productos desconocidos hasta entonces, lo que alentó la formación de una estructura monetaria. Oficinas de intercambio y comercio, agencias de importación y exportación, bancos, en resumen, una multitud de actividades hasta ahora innecesarias en el mundo del patriarcado rural, sólo experimentaron en sus proporciones adecuadas en las regiones minera[7]s.

Pero la gran transformación social provocada por este nuevo escenario europeizado de relaciones económicas sería la entrada de miles de inmigrantes. Además de los aproximadamente 15.000 portugueses que llegaron juntos la familia real, inglés, alemán y francés también llegaron a Brasil, por razones que van desde económicas a artísticas. El futuro país que nacería en 1822 ya marcaba características de un estado independiente.

Los inmigrantes eran mano de obra libre que, sumados a los trabajadores libres nacidos en Brasil, conformaban la clase media moderna de la que hablamos antes. Una clase diferente de la antigua casa rural, ocupando la parte intermedia de la jerarquía social, pero sin necesidad de la protección de su compadre. Los principios liberales y el individualismo, que había nado desde el siglo XVIII con la filosofía de la llustración, entraron en el inconsciente del habitante urbano. Una especie de hombre hecho a sí mismo de los trópicos poblaría el imaginario de la ciudad. 
Con el capitalismo mercantil abre un vacío fundamental para su mantenimiento y reproducción: la necesidad de capital cultural para operarlo. Las actividades comerciales, manufactureras, burocráticas y docentes - para estar en algunos ejemplos - requieren una forma de conocimiento sano técnico y utilitario para su funcionamiento, un hecho que contribuiría a la oposición del trabajo manual, hasta ahora comúnmente realizado por el esclavo o los más pobres. La clase media será el grupo que se apropiará de este conocimiento y, a través de él, se distanciará de los más humildes, los del trabajo pesado, del nivel de las bestias.

Para los abandonados y olvidados, las tareas descalificadas, típicas de la chusma, permanecen. Estos, en gran medida, como en el caso del trabajo doméstico, serán una continuación de la esclavitud, ahora bajo nuevas máscaras. La explotación directa de la energía muscular, que apenas nos distingue de un caballo o mula, con poco conocimiento incorporado, es la característica distintiva, si no la única, en relación con los trabajadores con un mayor grado de cualificación técnica. (Souza, 2018: 74).

Tanto esta nueva clase media, como la futura clase trabajadora mínimamente especializada, que llamaremos "clase media baja", o "proletaria", intentarán a toda costa diferenciarse de la población vista como "escoria", formada principalmente por negros y mestizos. Puesto que no tienen los medios de producción, al menos tratarán de imitar los valores simbólicos de las élites, reflexionando sobre la obsesión por la europeización de las costumbres y, a través de la educación formal y técnica, en el distanciamiento del trabajo manual, tan depreciado por los valores occidentales. Aquí tenemos nuestra primera manifestación concreta de prejuicios incrustada por la clase media moderna del siglo XIX.

Las cuestiones endógenas y exógenas en relación con la cuestión de los esclavos brasileños fueron determinantes para la maduración inicial del proceso de modernización de las relaciones laborales y la maduración del capitalismo industrial en el siglo XIX. Desde la independencia brasileña, Inglaterra ha estado presionando al estado nacional recién nacido para que demuestre sus compromisos con la 
extinción gradual del comercio de esclavos practicado desde mediados del siglo XVI. Los movimientos internos liderados por intelectuales liberales, como la propia élite del café, debatieron abiertamente la abolición.

Estos hechos, al principio, podrían señalar de una manera sui generis que el país, a su ritmo, podría estar consolidando su transición del capitalismo comercial al capitalismo industrial, porque el escenario que se abrió con la abolición de la esclavitud desplazaría no sólo una enormidad de capital a los sectores productivos, sino también la modernización de las relaciones de clase, superando las amalgamas del sistema esclavo obsoleto. Pero eso no es lo que pasó. La industrialización sólo se consolidaría en el siglo siguiente, bajo la batuta del estado, en los gobiernos Getúlio Vargas y Juscelino Kubitschek, así como en el período dictatorial. Superar la esclavitud, en su campo simbólico, nunca se superaría.

Incluso con la abolición consumada en 1888, un hecho que convirtió a Brasil en el último país del mundo en poner fin a la esclavitud formal, el escenario perverso de violencia física y simbólica continuó. Además, los negros liberados se encontraron con enormes dificultades en su inserción en el mercado laboral, ya que todavía tenían que competir con la fuerza laboral inmigrante, ahora estimulada deliberadamente como práctica estatal. Fue dentro de esta perversa relación de permanencia que, con el tiempo, se formó Brasil, concomitantemente con el proceso de urbanización, una clase de la población que fue completamente excluida de los principios básicos de la ciudadanía, [8]y esto también afectaría a sus próximas generaciones, un efecto que llamaremos la "bola de nieve turbi[9]a".

\section{EXCLUYENDO LA INDUSTRIALIZACION $Y$ LA IMAGINARIA BOURGEOISA DE LA CLASE MIDDLE}

La vieja orden racial no desapareció con el fin del trabajo esclavo. En cambio, se asimiló e integró en las nuevas estructuras sociales derivadas del desarrollo del trabajo libre. Según Fernandes (1974), la revolución burguesa desencadenada con el fin de la esclavitud sólo benefició a algunos segmentos de la sociedad brasileña. 
Entre los más favorecidos estaba la porción "blanca" de la población de origen europeo, corroborando las teorías del blanqueo en boga en el país. Este grupo se benefició de todas las transformaciones resultantes del crecimiento económico, el impulso industrializador, el proceso de urbanización y el desarrollo de una cultura urbana. La clase marginada, compuesta por afrodescendientes, permaneció al margen de la sociedad nacional, excluida en gran parte de todas las mejoras que estas transformaciones produjeron. Estos hechos señalaron que la desarticulación del trabajo esclavo en las últimas décadas del siglo XIX no estuvo acompañada de cambios sustanciales en el antiguo orden racial, caracterizado por prejuicios y discriminación. La marginación social de alrededor del $50 \%$ de los brasileños puso claramente de relieve los límites de la modernización económica del país.

Con el mantenimiento de los medios de producción en manos de la agroexportelita y de la clase industrial incipiente, fue en la ciudad y en su entorno cosmopolita que se consolidó el estilo de vida burgués y, junto con él, todo su simbolismo. Fue con el surgimiento de la clase media urbana, especialmente la centrada en las actividades intelectuales y financieras, que el sentido de la europeización y la propagación aduanera. La incorporación de los valores aristocráticos europeos puede percibirse en la adopción de un patrón de sabor y lujo que buscaba igualar al de las capas aristocráticas. En una especie de "canibalismo simbólico", la clase media más próspera introdujo prejuicios y patriarcado, pero con una ropa que se decía que era moderna.

En una dialéctica simbólica, la clase media es uno de los mejores elementos para que percibamos cómo la esfera pública y privada fueron fundamentales para su autoafirmación, reconocimiento y distinción. Incluso lejos del concepto moderno de "meritocracia", se p[10]ercibe cómo el arquetipo de los más "bien adaptados" resuena en el imaginario de la burguesía promedio. Merit reemplazó el derecho de nacimiento como una nueva forma de diferenciación social, así como la sofisticación intelectual, otro elemento que comenzó a distinguir a la clase media de las clases populares, todavía sin acceso a una educación pública gratuita y de calidad. 
La generalización de la familia de clase media, en la que la mujer se hizo cargo de sus hijos y de las tareas domésticas -controlando el trabajo de numerosos empleados-y el hombre participó en las actividades del mundo empresarial, es uno de los aspectos llamativos en este sentido, porque da al individuo el sentimiento de continuidad, viendo en sus hijos la posibilidad de continuar con el negocio familiar. Por lo tanto, la incorporación de valores aristocráticos, más que meras modas, fue parte del proceso de consolidación de la hegemonía política y social y la visión del mundo de la clase media sobre la sociedad[11].

Una vez establecido el universo simbólico burgués de la clase media brasileña, queda clara la percepción antagónica de éste hacia los otros grupos menos ricos y su intento de equiparse simbólicamente con las élites, estos más bien verdaderamente poseedores de los medios de producción y control real del país. Esta obsesión por parecerse a las élites no será, salvo en algunos casos, reconocida en el ámbito del efectivo, por lo tanto, su equivalencia simbólica por condición so[12]cial o prestigio permanece, y esto puede obtenerse o reconocerse a través de tres elementos: ocupación productiva (empleo), consumo y estilo de vida, todo plenamente adecuado para la sociedad capitalista moderna, o, más que eso, uno complementando al otro.

Con la conquista del estatus en la moderna sociedad meritocrática brasileña, las nuevas formas de prestigio pasan a formar parte de la nueva jerarquía social. Lo más importante para la clase media, además de la "virtud" de la imitación, es distanciarse unos a otros de las prácticas diarias de la "escoria" social. Beber vino en detrimento de la cachaza, escuchar música clásica en lugar de música popular, asistir a teatros, academias literarias y restaurantes caros para el exhibicionismo de la etiqueta, además de los viajes internacionales - con el derecho a los consejos de los pseudodelincuentes, alimentándose de la ambigua sensación de repulsión en lo nacional - son pequeños ejemplos de esta cosmovisión reduccionista.

\section{CAPITAL CULTURAL, INSTITUCIONES SOCIALES Y PREJUICIOS}

A diferencia de la visión culturalista identificada al principio de nuestro texto como una forma de explicar las desigualdades sociales y las relaciones de clase, los conceptos 
de subjetivación y justificar las diferencias sólo desde el punto de vista material individual, tenemos que partir de la comprensión sociológica de las instituciones primarias y secundarias de la socialización para comprender el fenómeno del odio de clase tan presente en la vida cotidiana.

En general, la socialización comienza en la familia, una institución en la que el individuo aprende el idioma $\mathrm{y}$, a través de ella, a comunicarse, a expresar necesidades, así como a sentimientos de incomodidad o bienestar. La investigación psicológica como piaget (2005) confirma la importancia de los padres y otros miembros de la familia en la formación de la personalidad de los niños. Estos estudios indican que al comienzo del proceso de socialización los miembros de la familia tienden a ser más decisivos que las personas con las que el niño entra en contacto sólo ocasionalmente. Encontramos aquí un problema: en la organización de la sociedad de esclavos brasileña se hizo todo lo que se hizo para evitar la construcción de lazos de solidaridad entre las poblaciones esclavizadas, y la primera institución combatida fue la familia, comprometiendo esta etapa de socialización. Cabe destacar que apenas había espacio para la constitución de los lazos sociales primarios en prisión, sin tener en cuenta las necesidades psíquicas y emocionales de los cautivos.

La dificultad de la organización familiar no es un mero fenómeno del pasado esclavo, sino que sigue siendo, en la debida proporción, entre las poblaciones más humildes, en los hijos, nietos y bisnietos de las antiguas generaciones de degradantes. Todo esto tendrá profundas consecuencias en futuras relaciones secundarias, especialmente en el aprendizaje escolar, causando menos posibilidades de prestigio en el mercado laboral. Las familias más débiles son generalmente gravadas como "inconfortadas" por las clases altas, especialmente por el discurso generalista de la clase media, que, desde la cuna, fue capaz de construir lazos de solidaridad que serán determinantes para el éxito futuro.

El caso actual de la explotación de la chusma brasileña para ahorrar tiempo de las tareas domésticas sucias y pesadas, lo que le permite utilizar el tiempo "robado" a un precio vil en actividades más productivas y bien pagadas, muestra una clara funcionalidad de miseria como la luz 
solar. Esta lucha de clases silenciosas exime a toda una clase de cuidado de niños y vida en el hogar, transformando el dinero que ahorra tiempo y califica el aprendizaje. La clase robada, en este caso, está condenada eternamente a desempeñar los mismos papeles secularmente serviles. (Souza, 2019: 85).

Ahorre tiempo en tareas manuales e invierta tiempo en actividades intelectuales. Como resultado, una mayor formación profesional y, en consecuencia, un mayor prestigio social; se establece un círculo que no tiene nada que ver con el mérito, o la capacidad personal, sino más bien con la apropiación de un mayor capital cultural.

Según Bourdieu (2004), los niños de familias adineradas tienden a tener un mayor rendimiento escolar que los jóvenes de familias pertenecientes a las clases populares. En la mayoría de los casos, esto se debe a que los estudiantes de las clases dominantes tienen un capital cultural que otros no pudieron acumular, no sólo en la escuela, sino también en la formación cultural de los padres, que enseñarían a sus hijos las demandas de mantener y ampliar su privilegiada situación social. Los niños en situaciones de fragilidad social no tienen esta red de protección, que tiende a enfrentar muchas más dificultades porque no tienen los conocimientos y prácticas valorados por la cultura dominante. No participarían en los valores cultivados por estas élites y, por esta razón, tenderían a considerar el aprendizaje escolar como una forma de violencia contra sus valores y prácticas sociales, explicando las altas tasas de deserción escolar de la escuela brasileñ[13]a.

En la escuela, podemos tener la mejor percepción práctica de la violencia simbólica. En ella, por ejemplo, es común que los estudiantes de clases populares se encuentren con un idioma, una práctica cultural y valores que no conocen porque no tienen un determinado patrimonio cultural, o, como señala Bourdieu, un capital cultural que les permite entenderlos o asimilarlos, comprometiendo su desempeño escolar, convirtiéndose en un impedimento impuesto por la propia institución y deslegitimando el desempeño de este estudiante. A pesar de esto, el estudiante no se da cuenta de que su bajo rendimiento escolar está determinado por factores sociales y por lo tanto 
a menudo termina inintroduciendo el fracaso, comprometiendo su autoestima en un momento crucial en su formación no sólo académica sino humana.

Teniendo como referencia el acceso y la continuidad en el sistema educativo formal como una de las principales posibilidades proclamadas por una sociedad que se considera "meritocrática", encontramos un ejemplo sutil de cómo se perpetúan las limitaciones impuestas por el pasado esclavo, pero casi invisibles. Si en el pasado pudiéramos percibir todo explícitamente desigual, debido al fenotipo y la exclusión explícita de los esclavos a las instituciones, hoy todo parece corregido debido a la creación de un sistema de educación pública, trasladando todas las responsabilidades de éxito o fracaso al alcance individual. Cubre el sol con el tamiz, porqu[14]e la mayoría de las poblaciones necesitadas son excluidas del capital cultural, deliberadamente apropiadas por la clase media y las élites, además de tener acceso a un sistema de servicio público ineficiente.

En el mundo capitalista, la falta de éxito material lo condena a la condición de fracaso. ¿Imagínate entonces estar desprovisto de capital material y también de capital cultural? Debido a que las formas de ascensión de clase en el sistema depredador del capital no son fáciles, el ciclo reproductivo de la pobreza y la exclusión tiende a perpetuarse desde el nacimiento a los que provienen de las clases más pobres. Esto dará lugar a la asignatura, además de menos posibilidades de constituir una formación que le permita competir con los niños de las clases adineradas, mucho más propensos a sufrir todo tipo de violencia física y simbólica.

A medida que la reproducción de la desigualdad de clase desde la cuna se reprime tanto consciente como inconscientemente, es el estereotipo del negro, fácilmente reconocible, el que identifica fácilmente al enemigo a ser masacrado y explotado. El "peligro negro" utilizado como contraseña para masacrar indefensos y quilombola durante siglos se continúa por otros medios en la masacre abierta, y hoy aplaudido sin pejo, de pobres y negros en barrios marginales y prisiones. Y no sólo eso. Como no había continuidad temporal entre la esclavitud -que destruye el alma desde dentro, humilla y degrada al sujeto, 
convirtiéndolo en cómplice de su propia dominación- y la producción de una chusma de inadaptados al mundo moderno, nuestro excluido heredó, sin una solución de continuidad, todo odio y cobarde desprecio por los más débiles y con menos capacidad de defenderse. (Souza, 2019: 88).

Pero, ¿por qué esa desigualdad no parece ser percibida por la clase media brasileña? Como dijimos al principio de este artículo, la teoría de las clases sociales tomadas por los criterios de ingresos es insuficiente para entender una composición social compleja como la brasileña, debilitada por las consecuencias de su pasado esclavo. En nuestra opinión, es necesario superar el mero sesgo económico para entrar en la historia de las mentalidades[15]. Un ciudadano de clase media tiende a pensar en ella como su clase, por lo que no tendría ninguna base instrumental para la percepción del otro, haciendo el ejercicio de la otra cosa miserable o a menudo inalcanzable. Esta ausencia de dialéctica produce personas prejuiciosas, carentes de percepción del otro, en un país insertado en el siglo XXI dentro de un orden de mercado competitivo, que va más allá de la esfera económica, llegando a la visión social, al pensamiento y a la percepción del mundo. El colonialismo mental termina dominando las mentes mientras mantiene el status quo.

\section{CONSIDERACIONES FINALES}

Rastrear una reconstitución histórica de la formación de la clase media brasileña y su arquetipo de prejuicio no es una tarea fácil debido a la ambiguedad del concepto de clase social misma. El factor que creemos que es esencial para este entendimiento es la esclavitud pasada, que interfiere dramáticamente en la comprensión del tejido social presente y brasileño. Sólo en el serial a largo plazo podemos construir la narrativa presentada aquí y nuestra argumentación para la comprensión de las clases desde el contexto sociocultural, rompiendo con el economicismo tradicional de las teorías de clase, a veces interpretadas por pensadores liberales, a veces por pensadores marxistas. 
Identificando la importancia del pasado esclavo para la configuración de mentalidades de clase perpetuadas por las instituciones sociales, podemos percibir las desigualdades y los estereotipos socialmente constituidos que parecen reproducirse ad infinitum.

La familia, la escuela, las organizaciones, todo esto promueve a lo largo de nuestra historia la reproducción de los privilegios de los grupos elitistas y de la clase media, que está camuflada con la tinta de análisis pseudocientíficos de la meritocracia, en uno de los países más desiguales del planeta. La falacia de que es posible el ascenso casi innato para algunos en detrimento de otros se incorporó al imaginario de la clase media tan consistentemente que logró penetrar incluso las capas populares, en el fenómeno que tratamos en el texto sobre la introjección de los prejuicios.

Nacer en la clase media y la clase media alta es casi sinónimo de la reproducción del éxito de las generaciones pasadas y la incorporación de privilegios que harán una diferencia total en el futuro. Parecen ser hechos triviales, pero adquirir desde una edad temprana la disciplina de estudio, asistir a ciertos ambientes, vivir con personas con el capital cultural necesario para sobresalir en las relaciones sociales, estudiar una lengua extranjera en el turno escolar y estar bien alimentado son pequeños ejemplos de privilegios que, sumados a cientos de otros, darán forma al futuro ciudadano exitoso, como si su mérito personal hubiera sido el gran diferencial de tal logro.

Naturalizar la violencia diaria contra las mujeres pobres, negras, entre otras minorías, es sintomática de la violencia que dio forma a la historia brasileña. Los ecos de la esclavitud se escuchan en cada muerte en la favela, en cada agresión cometida por la policía, en cada broma en el almuerzo del domingo contada en las mesas de las familias que ya han naturalizado el racismo como algo moralmente aceptable, como si no fuera degradante dignidad humana, transformando así la realidad de la clase media en una jaula de miedos, angustia y odio sistémico. 


\section{REFERENCIAS}

BONFIM, Paulo Ricardo. Educar, higienizar e regenerar: uma história da eugenia no Brasil. São Paulo: Paco, 2019.

BOURDIEU, Pierre. A economia das trocas simbólicas. São Paulo: Perspectiva, 2004.

BRAUDEL, Fernand. Escritos sobre a história. São Paulo: Perspectiva, 1978.

CARVALHO, José Murilo de. Cidadania no Brasil: o longo caminho. São Paulo: Civilização Brasileira, 2003.

DOWBOR, Ladislau. A era do capital improdutivo. São Paulo: Editora Novas Palavras, 2017.

FAUSTO, Bóris. História do Brasil. 6. ed. São Paulo: Edusp/FDE, 1997. . História concisa do Brasil. São Paulo :Edusp, 2002.

FERNANDES, Florestan. Revolução burguesa no Brasil: ensaio de interpretação sociológica. Rio de Janeiro: Zahar, 1974.

FROMM, Erich. Anatomia da destrutividade humana. Rio de Janeiro: Zahar, 1975.

KENNETH, Maxwell. A devassa da devassa. São Paulo: Paz e Terra, 1995.

KLEIN, Naomi. Sem logo: a tirania das marcas em um planeta vendido. Rio de Janeiro: Record, 2002.

PARSONS, Talcott. Social structure \& person. USA: Free Press, 2007.

PIAGET, Jean. A representação do mundo na criança. Curitiba: Ideias e Letras, 2005.

ROCHA, Sônia. Pobreza no Brasil. Rio de Janeiro: FGV, 2006.

SARTRE, Jean Paul. A prostituta respeitosa. Campinas: Papirus, 1992. 
SOUZA, Jessé. A classe média no espelho. Rio de Janeiro: Estação Brasil, 2018. A elite do atraso. Rio de Janeiro: Estação Brasil, 2019.

SUCUPIRA, Eduardo. Introdução ao pensamento dialético. São Paulo: Alfa-Omega, 1984.

VOVELLE, Michel. Ideologias e mentalidades. São Paulo: Brasiliense, 1987.

WEBER, Max. A ética protestante e o espírito do capitalismo. São Paulo: Companhia das Letras, 2007.

YOUNG, Michael. The rise of meritocracy. United Kingdom: Transaction Pub, 1994

\section{APPENDIX A}

\begin{tabular}{|c|c|c|c|c|c|c|c|c|c|c|}
\hline \multirow{3}{*}{ Grandes Regiões e car acteristicas selecionadas } & \multicolumn{10}{|c|}{$\begin{array}{l}\text { Taxa de frequência liquida a estabelecimento de ensino da população residente de } 6 \text { a } 24 \text { anos de idade, por grupos de idade e nivel de } \\
\text { ensino (\%) }\end{array}$} \\
\hline & \multicolumn{2}{|c|}{$\begin{array}{l}6 \text { a } 14 \text { anos, no ensino } \\
\text { fundamental }\end{array}$} & \multicolumn{2}{|c|}{$\begin{array}{l}6 \text { a } 10 \text { anos, nos anos } \\
\text { iniciais do ensino } \\
\text { fundamental }\end{array}$} & \multicolumn{2}{|c|}{$\begin{array}{l}11 \text { a } 14 \text { anos, nos anos } \\
\text { finais do ensino } \\
\text { fundamental }\end{array}$} & \multicolumn{2}{|c|}{$\begin{array}{l}15 \text { a } 17 \text { anos, no ensino } \\
\text { médio }\end{array}$} & \multicolumn{2}{|c|}{$\begin{array}{l}18 \text { a } 24 \text { anos, no ensino } \\
\text { superior }\end{array}$} \\
\hline & Taxa & $\mathrm{CV}(\%)$ & Taxa & CV $(\%)$ & Taxa & $\mathrm{CV}(\%)$ & Taxa & $\mathrm{CV}(\%)$ & Taxa & $\mathrm{CV}(\%)$ \\
\hline Brasil & 97,0 & 0,1 & 95,5 & 0,2 & 85,9 & 0,3 & 68,5 & 0,6 & 23,2 & 1,3 \\
\hline Norte & 96,6 & 0,2 & 95,0 & 0,4 & 79,4 & 1,0 & 59,7 & 1,8 & 17,7 & 3,3 \\
\hline Nordeste & 96,8 & 0,1 & 95,3 & 0,2 & 82,0 & 0,6 & 60,7 & 1,1 & 16,8 & 2,9 \\
\hline Sudeste & 97,3 & 0,2 & 95,7 & 0,3 & 89,2 & 0,5 & 76,5 & 1,0 & 25,8 & 2,4 \\
\hline Sul & 97,4 & 0,2 & 96,1 & 0,3 & 89,6 & 0,6 & 69,6 & 1,4 & 29,1 & 2,4 \\
\hline Centro-Oeste & 96,8 & 0,3 & 95,0 & 0,4 & 88,4 & 0,9 & 70,4 & 1,7 & 30,1 & 2,9 \\
\hline \multicolumn{11}{|l|}{ Situaçäo do dom icilio } \\
\hline Urbana & 97,1 & 0,1 & 95,5 & 0,2 & 87,2 & 0,3 & 70,6 & 0,7 & 25,6 & 1,4 \\
\hline Rural & 96,9 & 0,2 & 95,6 & 0,2 & 79,6 & 0,7 & 57,4 & 1,3 & 8,3 & 3,5 \\
\hline \multicolumn{11}{|l|}{ Sexo } \\
\hline Homem & 96,9 & 0,1 & 95,3 & 0,2 & 83,5 & 0,5 & 63,6 & 0,9 & 19,7 & 1,8 \\
\hline Mulher & 97,2 & 0,1 & 95,7 & 0,2 & 88,3 & 0,4 & 73,7 & 0,7 & 26,8 & 1,5 \\
\hline \multicolumn{11}{|l|}{ Cor ou raça (1) } \\
\hline Branca & 97,3 & 0,1 & 95,8 & 0,2 & 89,5 & 0,4 & 76,6 & 0,8 & 32,9 & 1,6 \\
\hline Preta ou parda & 96,9 & 0,1 & 95,3 & 0,2 & 83,7 & 0,4 & 63,5 & 0,9 & 16,7 & 1,8 \\
\hline \multicolumn{11}{|l|}{$\begin{array}{l}\text { Classes de percentual de pessoas em ordem } \\
\text { crescente de rendimento domiciliar per capita }\end{array}$} \\
\hline Até $20 \%$ & 96,6 & 0,2 & 94,9 & 0,2 & 78,9 & 0,6 & 54,7 & 1,3 & 6,6 & 4,5 \\
\hline Mais de $20 \%$ até $40 \%$ & 96,9 & 0,2 & 95,4 & 0,3 & 85,3 & 0,6 & 65,3 & 1,2 & 12,0 & 3,3 \\
\hline Mais de $40 \%$ até $60 \%$ & 97,5 & 0,2 & 96,1 & 0,3 & 90,1 & 0,6 & 73,9 & 1,0 & 20,1 & 2,6 \\
\hline Mais de $60 \%$ até $80 \%$ & 97,5 & 0,3 & 95,9 & 0,5 & 93,0 & 0,6 & 81,1 & 1,2 & 32,3 & 2,1 \\
\hline Mais de $80 \%$ & 97,8 & 0,3 & 96,1 & 0,5 & 95,0 & 0,5 & 90,7 & 0,8 & 58,3 & 1,5 \\
\hline
\end{tabular}

Fonte: IBGE Pesquisa Nacional por Amostr a de Domicilios Continua, 2017, segundo trimestre.

Nota: (1) Não são apresentados resultados para amarelos, indigenas e pessoas sem declaração de cor ou raça 


\section{APPENDIX B}

\begin{tabular}{|c|c|c|c|c|c|c|c|c|c|c|c|c|}
\hline \multirow{4}{*}{$\begin{array}{l}\text { Grandes Regiōes e } \\
\text { Unidades da Fede raçäo }\end{array}$} & \multicolumn{12}{|c|}{ Distribuição percentual da população, por classes de percentual de pessoas em ordem crescente de rendimento real efetivo domiciliar per capita e cor ou raça (\%) } \\
\hline & \multicolumn{4}{|c|}{ Total } & \multicolumn{4}{|c|}{ Entre os $10 \%$ com menores rendimentos } & \multicolumn{4}{|c|}{ Entre os $10 \%$ com maiores rendimentos } \\
\hline & \multicolumn{2}{|c|}{ Branca } & \multicolumn{2}{|c|}{ Preta ou parda } & \multicolumn{2}{|c|}{ Branca } & \multicolumn{2}{|c|}{ Preta ou parda } & \multicolumn{2}{|c|}{ Branca } & \multicolumn{2}{|c|}{ Preta ou parda } \\
\hline & Percentual & CV (\%) & Percentual & CV (\%) & Percentual & CV (\%) & Percentual & CV (\%) & Percentual & CV (\%) & Percentual & CV (\%) \\
\hline Brasil & 43,6 & 0,5 & 55,4 & 0,4 & 23,9 & 1,8 & 75,2 & 0,6 & 71,7 & 0,8 & 26,3 & 2,3 \\
\hline Norte & 20,1 & 1,9 & 78,4 & 0,5 & 12,5 & 6,8 & 84,8 & 1,3 & 34,2 & 3,8 & 64,4 & 1,9 \\
\hline Rondônia & 31,2 & 3,0 & 68,2 & 1,4 & 23,6 & 9,3 & 75,2 & 2,9 & 40,9 & 7,9 & 58,4 & 5,5 \\
\hline Acre & 19,1 & 4,3 & 79,9 & 1,1 & 14,1 & 12,5 & 85,3 & 2,1 & 31,8 & 8,2 & 67,7 & 3,8 \\
\hline Amazonas & 18,1 & 4,7 & 79,5 & 1,2 & 11,0 & 13,1 & 86,2 & 2,0 & 38,2 & 9,8 & 60,5 & 5,8 \\
\hline Roraima & 21,5 & 5,6 & 72,4 & 2,0 & 14,6 & 17,7 & 71,3 & 7,3 & 40,9 & 8,4 & 55,5 & 6,5 \\
\hline Pará & 18,2 & 3,3 & 80,6 & 0,8 & 11,8 & 12,6 & 85,8 & 2,2 & 30,0 & 5,5 & 68,9 & 2,4 \\
\hline Amapá & 19,3 & 6,5 & 80,3 & 1,6 & 10,6 & 26,6 & 87,7 & 3,6 & 25,9 & 13,4 & 73,4 & 4,8 \\
\hline Tocantins & 23,7 & 4,7 & 75,3 & 1,5 & 14,8 & 19,0 & 84,4 & 3,4 & 42,5 & 6,4 & 56,2 & 4,7 \\
\hline Nordeste & 24,8 & 1,2 & 74,6 & 0,4 & 18,7 & 3,3 & 80,8 & 0,8 & 42,8 & 2,7 & 56,4 & 2,0 \\
\hline Maranhão & 18,5 & 2,6 & 80,8 & 0,6 & 15,7 & 6,9 & 83,9 & 1,3 & 31,5 & 5,5 & 67,4 & 2,6 \\
\hline Pauí & 20,5 & 4,8 & 79,4 & 1,2 & 18,6 & 11,0 & 81,2 & 2,5 & 40,9 & 7,6 & 58,6 & 5,5 \\
\hline Ceará & 27,5 & 2,2 & 71,9 & 0,8 & 20,4 & 6,2 & 79,1 & 1,6 & 46,9 & 4,3 & 52,6 & 3,8 \\
\hline Rio Grande do Norte & 36,7 & 2,6 & 63,1 & 1,5 & 30,6 & 7,1 & 69,1 & 3,1 & 50,9 & 5,5 & 48,8 & 5,8 \\
\hline Paraba & 33,8 & 3,0 & 66,1 & 1,5 & 30,1 & 7,2 & 69,8 & 3,1 & 54,1 & 5,4 & 45,7 & 6,3 \\
\hline Pernambuco & 30,7 & 3,0 & 68,5 & 1,4 & 23,2 & 8,3 & 76,5 & 2,5 & 51,5 & 5,8 & 47,4 & 6,2 \\
\hline Alagoas & 23,4 & 2,8 & 76,1 & 0,9 & 21,8 & 6,3 & 77,9 & 1,8 & 36,1 & 6,6 & 63,5 & 3,8 \\
\hline Sergipe & 20,8 & 5,4 & 78,3 & 1,4 & 13,6 & 13,9 & 85,7 & 2,2 & 36,6 & 12,4 & 61,7 & 7,3 \\
\hline Bahia & 19,2 & 3,9 & 80,2 & 0,9 & 14,7 & 9,4 & 84,6 & 1,6 & 35,3 & 9,1 & 63,6 & 4,9 \\
\hline Sudeste & 51,2 & 0,9 & 47,6 & 1,0 & 35,2 & 2,8 & 64,2 & 1,5 & 78,1 & 1,1 & 19,0 & 4,6 \\
\hline Minas Gerais & 40,4 & 1,7 & 59,3 & 1,2 & 24,5 & 5,5 & 75,2 & 1,8 & 64,8 & 2,6 & 34,8 & 4,8 \\
\hline Espirito Santo & 39,2 & 2,6 & 60,2 & 1,7 & 22,5 & 10,6 & 77,2 & 3,1 & 64,5 & 3,0 & 35,2 & 5,6 \\
\hline Rio de Janeiro & 43,8 & 1,7 & 55,7 & 1,3 & 28,4 & 5,2 & 71,2 & 2,1 & 74,5 & 1,9 & 24,8 & 5,8 \\
\hline São Paulo & 60,1 & 1,2 & 38,1 & 2,0 & 46,8 & 3,7 & 52,4 & 3,3 & 83,1 & 1,4 & 12,3 & 9,0 \\
\hline Sul & 75,6 & 0,5 & 23,7 & 1,7 & 59,3 & 2,1 & 39,9 & 3,2 & 91,3 & 0,6 & 7,9 & 6,9 \\
\hline Paraná & 67,2 & 1,1 & 31,7 & 2,3 & 52,2 & 3,8 & 46,7 & 4,3 & 86,7 & 1,3 & 11,4 & 9,4 \\
\hline Santa Catarina & 82,8 & 0,7 & 16,9 & 3,4 & 68,5 & 2,9 & 31,2 & 6,4 & 92,8 & 0,9 & 6,8 & 11,7 \\
\hline Rio Grande do Sul & 79,6 & 0,9 & 20,0 & 3,5 & 64,2 & 3,3 & 35,2 & 6,1 & 94,4 & 0,9 & 5,5 & 15,4 \\
\hline Centro-Oeste & 36,3 & 1,4 & 62,6 & 0,8 & 25,0 & 4,5 & 74,0 & 1,5 & 56,2 & 3,4 & 41,0 & 4,0 \\
\hline Mato Grosso do Sul & 43,2 & 2,6 & 55,5 & 2,1 & 28,9 & 8,7 & 69,1 & 3,7 & 65,0 & 3,6 & 34,1 & 6,8 \\
\hline Mato Grosso & 31,8 & 3,2 & 67,0 & 1,5 & 23,7 & 12,3 & 74,9 & 3,9 & 54,4 & 4,8 & 43,9 & 6,0 \\
\hline Golás & 35,7 & 2,2 & 63,6 & 1,2 & 23,9 & 7,4 & 75,8 & 2,3 & 51,6 & 4,2 & 47,7 & 4,6 \\
\hline Distrito Federal & 36,7 & 4,1 & 61,6 & 2,4 & 22,8 & 11,0 & 76,5 & 3,3 & 59,3 & 10,5 & 29,1 & 10,0 \\
\hline
\end{tabular}

\section{APPENDIX C - REFERENCIAS DE FOOTNOTE}

2. Para o entendimento da financeirização do capitalismo e suas repercussões no mundo do trabalho, vide DOWBOR, Ladislau. A era do capital improdutivo. São Paulo: Editora Novas Palavras, 2017.

3. SARTRE, Jean Paul. A prostituta respeitosa. Campinas: Papirus, 1992. En esta pieza, el autor retrata cómo la introjección de los prejuicios, incorporada por la víctima, se naturaliza dentro de la sociedad del sur de los Estados Unidos.

4. BRAUDEL, Fernand. Escritos sobre a história. São Paulo: Perspectiva, 1978.

5. FROMM, Erich. Anatomia da destrutividade humana. Rio de Janeiro: Zahar, 1975. 
6. Uma das obras mais consistentes e rica em fontes primárias sobre a organização das regiões mineradoras é de KENNETH, Maxwell. El libertinado del libertinado. São Paulo: Paz e Terra, 1995.

7. Sobre o período em questão, vide FAUSTO, Bóris. História concisa do Brasil. São Paulo: Edusp, 2002.

8. Para um melhor entendimento sobre a construção do processo da cidadania brasileira, vide CARVALHO, José Murilo de. Cidadania no Brasil: o longo caminho. São Paulo: Civilização Brasileira, 2003.

9. Usamos metafóricamente la expresión "bola de nieve nublada", porque los negros, mestizos, indígenas, marrones, además de la población blanca marginada, engrosaron el contingente de "escoria" segregada de la sociedad jerárquica brasileña. Durante el siglo XIX, el racismo científico y los principios de la eugenesia se encuentran en América, particularmente en los eugenistas estadounidenses, sus principales portavoces. Aunque los prejuicios en el Brasil se limitan erróneamente a cuestiones fenotípicas, el papel desempeñado por los eugenistas en la estimulación de las políticas de blanqueo, asumido deliberadamente por el gobierno brasileño para purificar la genética de la población, es considerable. Esto contribuyó directamente al estímulo al racismo y la animalización de individuos considerados "inferiores". BONFIM, Paulo Ricardo. Educar, higienizar e regenerar: uma história da eugenia no Brasil. São Paulo: Paco, 2019.

10. En Brasil, el concepto de "meritocracia" impregna el sentido común y la demagogia. En nuestra opinión, sólo se entiende "meritocracia" si entramos en su origen en la literatura en la que el concepto nace de una manera satírica e irónica. Ver YOUNG, Michael. The rise of meritocracy. United Kingdom: Transaction Pub, 1994.

11. "Con el advenimiento de la cultura de masas en el siglo XX, el capitalismo crea un nuevo simbolismo de inclusión falsa, introduciendo en la sociedad contemporánea lo que llamamos la "supresión de la subjetividad", elevando el desarrollo del llamado "comportamiento mimético", es decir, el individuo habría dejado de desarrollar una 
personalidad propia, original, que lo pondría en conflicto y tensión con la realidad social establecida". KLEIN, Naomi (2009). Sem logo: a tirania das marcas em um planeta vendido. Rio de Janeiro: Record, 2002.

12. Tomamos como referência o conceito de status em WEBER, Max. La ética protestante y el espíritu del capitalismo. São Paulo: Companhia das Letras, 2007.

13. De acuerdo con los Apéndices A y B, podemos notar claramente los males históricos del proceso de exclusión de las poblaciones negras y marrones en su trayectoria educativa, distanciando a estos grupos de los mecanismos de acceso requeridos por la sociedad contemporánea para una vida digna, que exige una mejor colocación profesional, comprometiendo sus ingresos y su capacidad de entrar en el mundo capitalista.

14. La expresión popular brasileña se utiliza para describir medidas ineficaces para ciertos problemas.

15. VOVELLE, Michel. Ideologias e mentalidades. São Paulo: Brasiliense, 1987.

Enviado: Diciembre de 2019.

Aprobado: Febrero de 2020. 